\title{
VERIFICATION OF SERA FROM CATTLE AND PIGS FOR BRUCELLOSIS WITH FLUORESCENCE POLARISATION ASSAY
}

\author{
MARCIN WEINER, WOJCIECH IWANIAK, KRZYSZTOF SZULOWSKI, \\ AND MONIKA SZYMAJDA \\ Department of Microbiology, \\ National Veterinary Research Institute, 24-100 Pulawy, Poland \\ mpweiner@piwet.pulawy.pl
}

Received: April 3, 2013

Accepted: May 4, 2013

\begin{abstract}
Fluorescence polarisation assay (FPA) was evaluated as a potential tool improving specificity of serological diagnosis of brucellosis in cattle and pigs. The evaluation was performed by comparing the results of FPA with the results of rose Bengal test (RBT), serum agglutination test (SAT), complement fixation test, and indirect ELISA when problematic sera, regarded as false positive, were tested. Four hundred and seventy-five sera, including 201 porcine and 274 bovine samples, reacting positively in at least one classical serological assay were used. Only six bovine sera were FPA positive (two positive in SAT and RBT and four positive in SAT only). Different situation was observed when porcine sera were examined. Out of 201 sera, 109 were also positive in FPA. The studies confirmed that in cattle FPA enables to reduce highly the number of false positive reactions for brucellosis. On the other hand, in pigs, the method is a little more specific in comparison to other methods applied.
\end{abstract}

Key words: cattle, pigs, brucellosis, FPA, serological diagnosis.

Brucellosis is an important zoonosis and a significant cause of reproductive losses in animals. The genus Brucella (B.) encompasses ten species (13) and the classification depends mainly on differences in their pathogenicity and host preferences (7). The most important, worldwide distributed species are B. abortus, which causes brucellosis in cattle, B. melitensis - the main aetiological agent of ovine and caprine brucellosis, and $B$. suis, which is responsible for swine brucellosis (3). The laboratory diagnosis of brucellosis is mainly based on serological tests and the methods, which have been applied for years for diagnosing brucellosis: the rose Bengal test (RBT), serum agglutination test (SAT), complement fixation test (CFT), and indirect ELISA (iELISA) (20). Animals classified finally as serologically positive are slaughtered, and culture methods are used to isolate Brucella $(2,5)$. Molecular methods (PCR) are also used for identification the Brucella sp. molecular determinants (1, 5, 19). However, the similarity of the $\mathrm{O}$-antigenic side chain of Brucella LPS with other microbes has restricted the specificity of serological diagnosis resulting in false positive serological results (FPSR). Occurrence of these reactions in surveillance and diagnosis of brucellosis constitutes a very serious problem in many countries. Most commonly, FPSR are caused by infections with Yersinia enterocolitica O:9, possessing identical O-antigen lipopolysaccharide chain (LPS). While this organism may be rare in cattle, it is often found in the environment of pigs, causing diagnostic difficulties. On the other hand, Escherichia coli O157:H7 a microorganism often associated with cattle, was shown to cross react with Brucella sp. due to the presence of $\mathrm{N}$-acetylated-D-perosamine $(6,12)$.

The fluorescence polarisation assay (FPA) has a shorter history of use than classical serological assays. It has been recommended by the OIE as an additional testing procedure for brucellosis in most National Reference Laboratories (5, 20). Fluorescence polarisation measures the excitation by plane polarised light of a fluorescent molecule. Measurement of returned photons in the planes parallel and perpendicular to the excitation plane allows for the assessment of the rotation of fluorescent molecule (fluorophore). When other factors are constant, the rate of rotation of this molecule is inversely proportional to its size. Thus, the rotation of a fluorophore conjugated to, in this case, Brucella O-chain, will be slow if bound by Brucella antibodies. The FPA is rapid and requires no solid phase bound reagent or removal of excess reagents. It is host speciesindependent and can be conducted also with whole blood or milk $(4,10,11)$.

The aim of the study was to evaluate FPA as a potential tool improving specificity of serological diagnosis of brucellosis in cattle and pigs. The evaluation was done by comparing the results of FPA 
with the results of RBT, SAT, CFT, and iELISA when problematic sera were tested.

\section{Material and Methods}

Sera samples. Four hundred and seventy-five sera, positive at least in one serological test, including 274 sera from cattle and 201 sera from swine, were used. The sera originated from routine and confirmatory investigations conducted in 2010-2012 by the National Reference Laboratory for Brucellosis in the National Veterinary Research Institute in Pulawy (NVRI). The bovine sera were from animals from territory of Poland where B. abortus has not been isolated since 1980. In case of porcine sera, the epidemiological investigations revealed that all animals originated from industrial indoor pig farming with no history of brucellosis. The analysis of serological testing, repeated in such situations at least twice, with $30 \mathrm{~d}$ intervals, revealed that in examined herds a low percentage of positive results was observed. The antibody titres observed in CFT and SAT were low, absorbance values of positive samples in ELISA were closed to the cut-off value and fast decline or disappearing of antibodies in high percentage of animals was observed. These features are typical for FPSR (15), and all these sera were classified as negative for brucellosis. The breeding of animals was continued with no negative consequences.

Traditional serological tests. The RBT, SAT, and CFT were performed in accordance with official guidance (20). The iELISA for testing of bovine sera was performed using commercial brucellosis serum ELISA kit (Pourquier, France). For testing of sera from pigs by iELISA, the diagnostic kit elaborated in NVRI, as described previously, was used (16).
Fluorescence polarisation assay. FPA was conducted as described previously (18) with the major modification concerning establishing of a cut-off value. In detail, the cut-off, which depends on the mean value of millipolarisation units $(\mathrm{mP})$ for three replicates of the negative control was previously appointed and calibrated to $70-95 \mathrm{mP}$ according to the manual obtained from the manufacturer. In the study, the FPA reader (Diachemix, USA) was calibrated using control of strong positive, weak positive, and negative serum in accordance with recommendations of OIE Manual (20). The results were interpreted as negative, if values of the samples were less than $10 \mathrm{mP}$ above the intra-laboratory established mean value of negative control. Any results greater than $20 \mathrm{mP}$ above the mean value of negative control were regarded as positive. Samples in the range of 10-20 mP, which were recognised as suspected, were retested using double volume $(20 \mu \mathrm{L})$ of the serum samples.

\section{Results}

The frequency of distributions of $\mathrm{mP}$ values obtained in FPA in testing of bovine and porcine sera are presented in Fig. 1. Almost all bovine sera, except six, had values less than $20 \mathrm{mP}$ above the mean value of negative control and were classified as negative. The values of positive samples were situated in a range of 20-30 mP (two samples) and 30-40 mP (four samples). On the contrary, most porcine serum samples (109 out of 201) examined in FPA had values exceeding more than $20 \mathrm{mP}$ above the mean value of negative control and were classified as positive. The values of positive samples were scattered in different ranges.

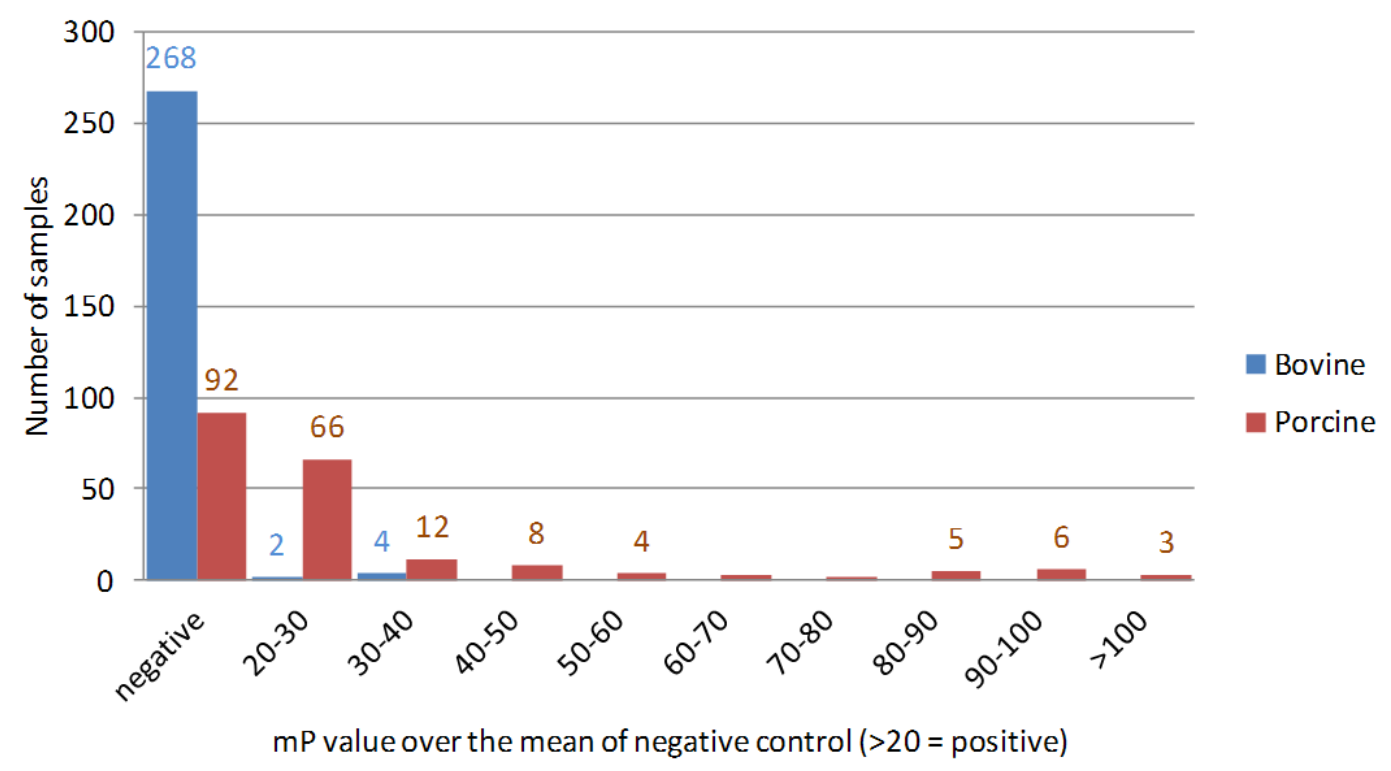

Fig. 1. Distribution of the $\mathrm{mP}$ values obtained in FPA in testing bovine and porcine sera 
Table 1

Comparison of the results obtained in classical tests and FPA used in evaluation of Brucella antibodies in bovine and porcine sera

\begin{tabular}{|c|c|c|}
\hline \multirow{2}{*}{ Origin of the samples } & \multicolumn{2}{|l|}{ Number of positive samples } \\
\hline & Classical tests & FPA \\
\hline \multirow{4}{*}{ Bovine sera $(n=274)^{1}$} & RBT-positive only $(\mathrm{n}=12)$ & 0 \\
\hline & SAT-positive only $(\mathrm{n}=27)$ & 4 \\
\hline & RBT-positive and SAT-positive $(n=235)$ & 2 \\
\hline & & Total $=6$ \\
\hline \multirow{8}{*}{ Porcine sera $(n=201)$} & RBT-positive only $(\mathrm{n}=3$ ) & 1 \\
\hline & SAT-positive only $(n=13)$ & 10 \\
\hline & CFT-positive only $(\mathrm{n}=15)$ & 12 \\
\hline & ELISA -positive only $(n=9)$ & 8 \\
\hline & RBT-positive and SAT-positive $(n=6)$ & 2 \\
\hline & CFT-positive and SAT-positive $(n=13)$ & 7 \\
\hline & RBT,SAT, CFT, iELISA positive $(\mathrm{n}=142)$ & 69 \\
\hline & & Total $=109$ \\
\hline
\end{tabular}

${ }^{1}$ all sera were negative in CFT and iELISA

Table 1 summarises the results of serological examination of sera from cattle and pigs for brucellosis obtained in traditional tests and FPA. Among 274 bovine sera, 12 were positive only in RBT, 27 were positive only in SAT, whereas 235 sera were positive in both tests. Six sera, two positive in RBT and SAT, and four SAT-positive were also positive in FPA with $\mathrm{mP}$ within the range of $20-30$ and $30-40$ over the mean negative control, respectively. All the remaining 268 sera were negative in FPA, similarly as in CFT and iELISA.

Much more different situation was observed when sera from pigs were tested (Table 1). Among 201 porcine sera, 40 were positive in only one of the classical serological assays and among them, 31 were FPA positive. The serum positive only in RBT gave results greater than $20 \mathrm{mP}$ over the mean negative control and was classified as FPA-positive. Among 13 SAT-only positive samples, ten of them were also positive in FPA and among 15 CFT-only positive samples, 12 of them were classified as positive in FPA. The iELISA-only positive sera (9) in eight cases gave positive results in FPA. In the study, it was observed that among samples, which were positive in two of the assays used: RBT and SAT-positive (6), or CFT and SAT-positive (13), the positive results in FPA were observed in two and seven cases, respectively. Among sera, which were positive in all classical tests - RBT, SAT, CFT, and iELISA (142), 69 samples were FPA positive.

\section{Discussion}

FPA is a method, which is increasingly used in diagnosis of animal brucellosis and has many advantages: it is very quick, does not require specialised staff, may be performed under field conditions, also with battery supply, and because data are obtained electronically, it is an objective test. The FPA has been validated for a number of species, including cattle, pigs, and humans $(4,8,9)$. As the method gained the status of prescribed OIE test for international trade for both cattle and pigs (20), the aim of the study was to evaluate usefulness of FPA under Polish conditions and, possibility, to adopt the method for routine diagnosis of brucellosis. Taking into consideration that in Poland $B$. abortus has not been isolated for many years and $B$. suis infections are listed sporadically $(16,17)$, while the serious problem are false-positive reactions, the objective was to look for more specific methods. Therefore, the evaluation was done on false-positive bovine and porcine sera. The earlier studies of Nielsen et al. $(10,11)$ concerning cattle and pigs showed a high specificity of the test. In the previous investigations performed on various batches of bovine sera, where criteria of qualification of FPA results were different from the currently presented due to manufacturer's instructions, a full correlation between the results of examination of negative samples tested in FPA and traditional tests was also revealed (18). On the contrary, discrepancies between the results of FPA and other serological methods were observed when sera with positive results in various tests were examined (18). The present studies confirmed that in cattle, the FPA enables to reduce highly the number of observed positive reactions for brucellosis (only six positive results out of 274). On the other hand, in pigs the method is not as accurate, as far as specificity in comparison to other methods is concerned (109 positive results out of 201). In our opinion, FPA has not the capability to differentiate antibodies to cross-reacting microorganisms, such as $Y$. enterocolitica $\mathrm{O}: 9$ from antibodies to Brucella, which was suggested by other authors (14). Yersinia enterocolitica O:9, the bacterium possessing 
identical O-antigen lipopolysaccharide chain (LPS), is often found in the environment of pigs, causing diagnostic difficulties. In the study, some of the examined sera originated from pigs in which $Y$. enterocolitica $\mathrm{O}: 9$ was present (data not published).

Taking into consideration the diagnostic value, therein specificity, and other advantages of the FPA, such as the speed of obtaining results, the objectivity of results interpretation, as well as the cost, this method should be included into routine serological examinations for bovine brucellosis. The use of this method is particularly valuable in countries such as Poland that is officially free from brucellosis, and the disease practically does not exist. The application of the more specific method, enabling reduction of number of false positive results is particularly important. It allows to avoid necessity of slaughtering of sero-positive animals and imposing restrictions - blockade of farms, animal movements, restriction on milk. Additionally, it contributes to reduction of costs of retesting of animals and epidemiological investigations. On the other hand, in pigs the method does not constitute a tool for resolving all problems, particularly relevant to the presence of cross-reacting antibodies. Results obtained in FPA still do not allow making an unambiguous diagnosis regarding cross-reactions. Further evaluating studies, especially on porcine brucellosis, are needed.

\section{References}

1. Bricker B.J., Ewalt D.R., Olsen S.C., Jensen A.E.: Evaluation of the Brucella abortus species-specific polymerase chain reaction assay, an improved version of the Brucella AMOS polymerase chain reaction assay for cattle. J Vet Diagn Invest 2003, 15, 374-378.

2. Corbel M.J., Gill K.P.W., Thomas E.L.: Methods for the identification of Brucella. Central Veterinary Laboratory, New Haw, Weybridge, UK, 1983, pp. 1-63.

3. Cvetnic Z., Mitak M., Ocepek O., Lojkic M., Terzic S., Jemersic L., Humski A., Habrun B., Sostaric B., Brstilo M., Krt B., Garin-Bastuji B.: Wild boars (Sus scrofa) as reservoirs of Brucella suis biovar 2 in Croatia. Acta Vet Hung 2003, 51, 465-473.

4. Gall D., Nielsen K., Forbes L., Davis D., Elzer P., Olsen S., Balsevicius S., Kelly L., Smith P., Tan S., Joly D.: Validation of the fluorescence polarization assay and comparison to other serological assays for the detection of serum antibodies to Brucella abortus in bison. J Wildl Dis 2000, 36, 469-476.

5. García-Yoldi D., Marín C.M., De Miguel M.J., Muñoz P.M., Vizmanos J.L., López-Goñi I.: Multiplex PCR assay for the identification and differentiation of all Brucella species and the vaccine strains Brucella abortus S19 and RB51 and Brucella melitensis Rev1. Clin Chem 2006, 52, 779-781.

6. Garin-Bastuji B., Hummel N., Gerbier G., Cau C., Pouillot R., Da Costa M., Fontaine J.J.: Nonspecific serological reactions in the diagnosis of bovine brucellosis: experimental oral infection of cattle with repeated doses of Yersinia enterocolitica O:9. Vet Microbiol 1999, 66, 223 233.

7. Halling S.M., Peterson-Burch B.D., Bricker B.J., Zuerner R.L., Qing Z., Li L.L., Kapur V., Alt D.P., Olsen S.C.:
Completion of the genome sequence of Brucella abortus and comparison to the highly similar genomes of Brucella melitensis and Brucella suis. J Bacteriol 2005, 187, 2715 2726.

8. Konstantinidis A., Minas A., Pournaras S., Kansouzidou A., Papastergiu P., Maniatis A., Stathatis N., Hadjichristodoulou C.: Evaluation and comparison of fluorescence polarization assay with three of the currently used serological tests in diagnosis of human brucellosis. Eur J Clin Microbiol Infect Dis 2007, 26, 715-721.

9. Lucero N.E., Escobar G.I., Ayala S.M., Silva Paulo P., Nielsen K.: Fluorescence polarization assay for diagnosis of human brucellosis. J Med Microbiol 2003, 52, 883-887.

10. Nielsen K., Gall D., Bermudek R., Renteria T., Moreno F., Corral A., Monroy O., Monqe F., Smith P., Widdison J., Mardrueno M., Calderon N., Guerrero N., Tinoco R., Osuna J., Kelly W.: Field trial of the brucellosis fluorescence polarization assay. J Immunoassay Immunochem 2002, 23, 307-316.

11. Nielsen K., Gall D., Smith P., Kelly W., Yeo J., Kenny K., Heneghan T., McNamara S., Maher P., O'Connor J., Walsh B., Carroll J., Rojas X., Rojas F., Perez B., Wolff O., Bufoni L., Salustio E., Gregoret R., Samartino L., Dajer A., Luna-Martinez E.: Fluorescence polarization assay for the diagnosis of bovine brucellosis: adaptation to field use. Vet Microbiol 2001, 80, 163-170.

12. Nielsen K., Smith P., Widdison J., Gall D., Kelly L., Kelly W., Nicoletti P.: Serological relationship between cattle exposed to Brucella abortus, Yersinia enterocolitica 0:9 and Escherichia coli O:157:H7. Vet Microbiol 2004, 100, 25-30.

13. Scholz H.C., Nöckler K., Göllner C., Bahn P., Vergnaud G., Tomaso H., Al Dahouk S., Kämpfer P., Cloeckaert A., Maquart M., Zygmunt M.S., Whatmore A.M., Pfeffer M., Huber B., Busse H.J., De B.K.: Brucella inopinata sp. nov., isolated from a breast implant infection. Int $\mathrm{J}$ Syst Evol Microbiol 2010, 60, 801-808.

14. Silva Paulo P., Vigliococco A.M., Ramondino R.F., Marticorena D., Bissi E., Briones G., Gorchs C., Gall D., Nielsen K.: Evaluation of primary binding assays for presumptive serodiagnosis of swine brucellosis in Argentina. Clin Diagn Lab Immunol 2000, 7, 828-831.

15. Szulowski K., Iwaniak W., Pilaszek J.: Porcine brucellosis in Poland, problems accompanying serological surveys conducted in 1995-2000. Bull Vet Inst Pulawy 2001, 45, 153-161.

16. Szulowski K., Iwaniak W., Złotnicka J., Weiner M., Zaręba Z., Czępińska H.: International trade - a potential origin of brucellosis in pigs. Med Weter 2011, 67, 64-66.

17. Szulowski K., Iwaniak W., Weiner M., Złotnicka J., Szymajda M., Zaręba Z., Czępińska H.: Diagnosis and epidemiological condition of bovine brucellosis in Poland. Med Weter 2012, 68, 110-113.

18. Weiner M., Iwaniak W., Złotnicka J., Szulowski K.: Diagnosis of bovine brucellosis using traditional serological techniques and fluorescence polarisation assay. Bull Vet Inst Pulawy 2010, 54, 489-493.

19. Weiner M., Iwaniak W., Szulowski K.: Comparison of PCR-based AMOS, Bruce-Ladder and MLVA assays for typing of Brucella species. Bull Vet Inst Pulawy 2011, 55, 625-630.

20. World Organisation for Animal Health (2012): Manual of Diagnostic Tests and Vaccines for Terrestrial Animals 2012. Part 2, Section 2.4. Chapter 2.4.3. Bovine brucellosis (version adopted in May 2009). Section 2.8. Chapter 2.8.5. Porcine brucellosis (version adopted in May 2009). OIE, Paris, 2012. 